TranscUlturAl, vol. 1, (4) 2011, 123-146.

http://ejournals.library.ualberta.ca/index.php/TC

\title{
Le «SARS» et les maux identitaires chinois. Néologismes, métissage et tradition de la traduction
}

\author{
Florent Villard \\ Institut des Etudes Transtextuelles et Transculturelles (IETT) \\ Université de Lyon (Jean Moulin-Lyon 3)
}

L'épidémie de pneumopathie atypique de l'année 2003 par son origine chinoise et son expansion mondiale peut être prise comme l'allégorie d'une trajectoire qui serait allée à rebours du «sens» pris par l'histoire culturelle chinoise moderne.

Initiée avec la guerre de l'opium en 1839, la politique impérialiste des puissances euro-américaines et du Japon s'affermit considérablement à partir de la fin du xix siècle lorsque les nations se partagent le pays en zones d'influences, que les quartiers coloniaux se multiplient dans les grandes métropoles et que les capitaux et firmes étrangers s'installent massivement en Chine. En insistant sur son caractère fragmenté, multiple et partiel, Shu-mei Shih considère le «semi-colonialisme» comme «les effets spécifiques de la présence de différentes puissances impériales en Chine réparties en pointillés sur les territoires de la côte est » (Shih 37).

Sous l'effet de ce colonialisme partiel, l'histoire de la modernité depuis le milieu du $\mathrm{XIX}^{\mathrm{e}}$ siècle fut aussi celle d'un déplacement culturel - pratiques, idées, mots, textes, imaginaires - de l'espace socio-historique euro-américain vers la Chine, en passant par l'intermède du Japon. Les transformations sociales et culturelles majeures qui se sont produites dans les grandes métropoles chinoises pendant la première moitié $\mathrm{du} \mathrm{xx}^{\mathrm{e}}$ siècle correspondaient à une entrée brutale dans la modernité, qui se trouvait aussi être, pour la Chine, un processus d'acculturation. Car si ces bouleversements étaient internes à la société chinoise, ils ne s'en trouvaient pas moins très fortement modelés et informés par le poids de l'influence comme de la présence du capitalisme et de la culture moderne occidentale.

Dés lors, l'invention massive de néologismes pendant cette période servait le plus souvent à traduire des mots issus des langues européennes et/ou du japonais pour dire les nouvelles pratiques, les nouveaux concepts, les nouveaux objets qui accompagnaient cette modernité culturelle, littéraire, politique, technique et scientifique. Certains mots ont 
TranscUlturAl, vol. 1, (4) 2011, 123-146.

http://ejournals.library.ualberta.ca/index.php/TC

conservé aujourd'hui une couleur exotique - c'est le cas, par exemple, de asipiling, ou «aspirine », ou de shafa, ou «sofa» - mais la plupart ne gardent plus aucune trace de leur histoire transculturelle et ont été complètement «sinisés».

Les mots nouveaux ne cessent jamais d'apparaittre dans une langue donnée. En postulant l'existence de frontières, instables et poreuses, intra- et extra- linguistique, il est possible de dire qu'ils émergent à la fois de la multiplicité sociale et culturelle interne à une « formation linguistique » ${ }^{1}$ et de la traduction de mots issues d'autres langues. Ce phénomène universel du métissage des langues et du voyage des mots ne doit pas occulter la singularité de l'histoire culturelle chinoise moderne dans ce domaine. C'est cette réalité historique qui amène Jean-François Billeter à préciser que « la plus grande partie des termes utilisés aujourd'hui en matière économique, sociale, politique, en philosophie et dans les sciences humaines sont des néologismes calqués sur des termes européens » $(78)^{2}$.

La langue d'une nation est un élément central de l'invention de son identité. Benedict Anderson note que le développement du capitalisme de l'imprimerie, élément de diffusion d'une langue vernaculaire commune, joua un rôle crucial dans la constitution d'une conscience nationale et l'invention de la nation en tant que "communauté imaginée » (Anderson). De plus, la langue nationalisée et standardisée, bien que toujours hybride et mêlée à d'autres langues, n'en est pas moins supposément, et dans l'imaginaire, l'élément qui met en relation les contemporains avec les ancêtres de la nation. Alors que cette identité linguistique entre le présent et le passé est surtout mythique et construite a postériori, elle n'en conserve pas moins une portée symbolique et politique très forte. Enfin, comme la « race », « l'ethnie », la culture ou les valeurs, la langue, dans une perspective toujours politique, peut-être érigée comme un critère identitaire et une caractéristique essentielle de la nation.

Dans une Chine contemporaine engagée dans un important renouveau du discours culturaliste, la langue et l'écriture, en tant que symboles essentialistes de l’identité chinoise,

\footnotetext{
1 «Une formation linguistique est un ensemble plutôt chaotique de dialectes, voire de langues en formation, de dialectes sociaux ou de générations, de jargons et registres, d'argots et autres langues secrètes, de styles, individuels et de groupes, de genres de discours et autres jeux de langage. C'est cet ensemble instable et en état de variation continue, chaque composante ayant son rythme et sa temporalité propres, qu'on appelle par abstraction (inévitable) et fétichisation (nullement innocente) l'anglais. » (Lecercle 196).

2 Dans Translingual Practice, Lydia Liu se penche sur la question des néologismes et interroge la création de ces mots en insistant sur la réinvention des concepts lorsqu'ils arrivent dans un nouveau contexte culturel. De la fin de la dynastie des Qing jusqu'à 1949, Lydia H. Liu cite différentes études chinoises et japonaises qui évaluent à un minimum d'environ mille deux cent le nombre de néologismes issus des Kanji Japonais, dont près de la moitié seraient déjà des emprunts aux langues européennes (18).
} 
TranscUlturAl, vol. 1, (4) 2011, 123-146.

http://ejournals.library.ualberta.ca/index.php/TC

sont aussi l'objet d'enjeux politiques nationalistes ${ }^{3}$. C'est ce discours politique autour de la langue comme facteur d'identité nationale qui fait l'objet de ce texte. Dans les médias de langue chinoise (presse écrite et internet), la question, au demeurant dérisoire, de la juste appellation à donner au virus du SARS n'a pas manqué de révéler cette dimension politique : les uns arguant la défense de l'identité nationale, les autres, l'ouverture et l'adaptation aux normes internationales. Nous essayons de donner une perspective historique à cette querelle en montrant que le rapport à la langue et l'écriture, et la relation de celle-ci avec la construction politique de l'identité moderne de la Chine, fut profondément modifié entre la période républicaine, première modernité chinoise, et le moment contemporain. Il s'agit surtout d'insister sur l'histoire transculturelle du vocabulaire de la pensée intellectuelle en Chine moderne et de s'essayer à déconstruire la dialectique dominante des rapports entre la Chine et l' «Occident» qui oscille sans cesse entre la posture universaliste et son double culturaliste. Cette opposition ne s'avère pas pertinente du point de vue de l'histoire, car si les revendications particularistes s'imaginent positionnées contre un certain universalisme moderne, elles sont pourtant le produit même de la modernité. Le nationalisme culturel, chinois (ou japonais), n'ayant pu faire exister son objet (la nation) - imaginé comme naturel, indépendant et homogène - que dans le cadre de la perspective universaliste moderne, comme prisonnier de sa propre image construite par le discours de l'Occident (Sakai 153177). Le dépassement de cette représentation dichotomique en trompe l'œil réside dans la prise en compte des connections culturelles et linguistiques entre la Chine et l'Europe, il s'agit de montrer l'entrelacement des histoires sans confondre l'Europe avec le moderne en la positionnant comme le sujet unique et dominant de l'Histoire. Derrière les signifiants de la Chine contemporaine se cachent des phénomènes d'échanges et de traductions produits de déplacements entre différents contextes historiques qui ne se laissent pas plus représenter par une perspective historique universelle que par la narration d'une histoire nationale continue, indépendante et homogène.

\footnotetext{
3 Pour une analyse théorique approfondie du nationalisme culturel en Chine contemporaine, lire Yingjie Guo, Cultural Nationalism in Contemporary China: The Search for National Identity under Reform ; voir aussi, en français, la somme éclairante de Terence Billeter sur l'exploitation nationaliste de la figure mythique de Huangdi par le régime communiste : L’Empereur Jaune: Une tradition politique chinoise.
} 
TranscUlturAl, vol. 1, (4) 2011, 123-146.

http://ejournals.library.ualberta.ca/index.php/TC

\section{Le virus et ses mots}

Après une période d’ignorance et de mutisme politique, l'épidémie de pneumopathie atypique qui s'est abattue sur la Chine et le monde au printemps 2003, fut relayée de façon spectaculaire par les médias chinois. Il est raisonnable de penser que si cet événement a pris une telle ampleur médiatique, c'est en raison des catégories sociales et des régions touchées par l'épidémie. La propagation dramatique du virus du sida dans la province du Henan à partir du milieu des années 1990 avait été consciencieusement cachée par les autorités chinoises. Les premiers malades spectaculaires du SARS (après les Chinois du Guangdong) furent un homme d'affaires de Hong Kong et un médecin français travaillant au Vietnam. Il n'est pas inutile de se demander ce qu'il en aurait été de la représentation et de l'impact médiatique du virus si celui-ci était resté confiné dans les profondeurs des campagnes chinoises. Sans ces malades, médiatiques et surtout mobiles, le silence embarrassé de l'Etat chinois aurait pu se poursuivre.

L'histoire en a voulu autrement et cette crise, d'abord chinoise, est devenue mondiale. Un événement particulier localisé, phénomène hier inconnu de tous, non répertorié, s'est produit en Chine puis s'est répandu sur une partie non négligeable de la planète. Les conséquences sanitaires furent, au regard de la dissémination médiatique du virus, très limitées. Toutefois, la diffusion et la narration de cet événement se fit à l'échelle de la mondialisation et des technologies contemporaines de communication. Le discours sur cette maladie voyagea finalement des campagnes cantonaises - il sortait de la bouche des malades et des services sanitaires locaux - jusqu'à l'Organisation Mondiale de la Santé (OMC), instance universelle et scientifique transcendant les souverainetés locales dans les cas d'alertes sanitaires transnationales.

Informée de l'existence d'un syndrome nouveau par un médecin de l'Hôpital français de Hanoi, l'organisation identifia la maladie avec une rapidité exceptionnelle et lui donna officiellement un nom le 15 mars 2003 : «Severe Acute Respiratory Syndrom », ou «SARS ». ${ }^{4} \mathrm{Il}$ faut cependant relever que cette appellation fut établie seulement après que l'OMS eut identifié plus précisément les symptômes que le virus provoquait sur les malades. Si cette l'alerte au coronavirus ne fut publiquement révélée qu'après la contamination de l'hôpital de la capitale vietnamienne, le SARS et s'était répandu depuis début février à Hong Kong.

$4 \quad$ Sur la chronologie de cette épidémie, voir l'article de Paul Benkimou et Sandrine Blanchard : «SARS, le roman d'un serial killer ». 
TranscUlturAl, vol. 1, (4) 2011, 123-146.

http://ejournals.library.ualberta.ca/index.php/TC

Longtemps avant que l'OMS ne trouve un nom au virus, les populations et les autorités locales chinoises avaient nommé le phénomène, qui sévissait déjà depuis plusieurs mois déjà dans les campagnes du sud-est de la Chine, à partir des observations et connaissances qu'elles avaient obtenues sur la maladie. Le 22 décembre 2002, l'Institut de Recherche sur les Maladies Respiratoires de Canton $^{5}$ avait déjà identifié le mal et proposé l'appellation suivante : «chuanranxing feidianxing feiyan », en abrégé «feidian ». Le mot signifiait littéralement « pneumopathie atypique contagieuse » et reflétait le fait que les symptômes de la maladie ne correspondaient pas aux critères classiques de cette affection. Ce terme de «pneumopathie atypique» fut celui par lequel, dans un premier temps, l'OMS et les médias mondiaux évoquèrent l'épidémie. Lorsque, au mois de mars, l'épidémie fut révélée par les média chinois, le mot qui circula fut celui de «feidian».

A la suite de l'identification du virus par l'OMS et de la proposition du terme scientifique de "SARS ", est apparu ici ou là dans les médias chinois - presse écrite et télévision - soit le sigle "SARS » en lettres romaines soit une translittération de l'abréviation qui, en pinyin, donnaient "sasi », "shasi » ou encore "shashi ». Les caractéristiques de l'écriture chinoise font que les différences produites par la traduction touchent non seulement le mot et sa morphologie, la sémantique, la prononciation mais aussi le système de notation.

Les pratiques furent multiples au sein des différents médias de langue chinoise (RPC, Taiwan, HK, Diaspora, Singapour) : on pouvait trouver le mot chinois «feidian », le xénisme «SARS » ou plus souvent les calques phonétiques de ce dernier terme pour nommer le virus. Au printemps 2003, en Chine populaire, d'après Yu Chong du Bureau de la linguistique pragmatique au Ministère de l'Education, le terme " feidian » était de loin le plus populaire alors que «SARS » se trouvait plutôt confiné à un usage dans les milieux scientifiques. Il faut préciser que la situation des médias en Chine populaire était particulière par rapport à ceux des autres média de langue chinoise au sein desquels l'appellation « feidian » n'était que très peu usitée. On notera que la BBC et VOA employaient le calque chinois « sasi » sur leurs sites internet. Les médias de la diaspora chinoise au Canada employaient tantôt "SARS », tantôt «feidian », quant à ceux de Singapour, c'était à la fois «SARS » et «shasi ». A HongKong, on trouvait les trois appellations avec certaines transcriptions phonétiques inédites comme «shashi ». Pour l'année 2003 et selon les statistiques officielles, le terme « feidian» se

$5 \quad$ Guangzhou buxi jibing yanjiusuo 
TranscUlturAl, vol. 1, (4) 2011, 123-146.

http://ejournals.library.ualberta.ca/index.php/TC

positionnait devant « le vaisseau Shenzhou 5 » et « la guerre d'Irak » au rang des expressions les plus répandues dans quatorze des plus importants quotidiens de Chine populaire ${ }^{6}$.

\section{Suivre la science et le monde avec le « SARS »}

La dimension purement linguistique de cette question terminologique est ici très secondaire et sans véritable intérêt sur le plan intellectuel. Il suffit ici de rappeler, avec Saussure, ce que les signes linguistiques ont d'arbitraire et de conventionnel pour confirmer qu'il n'y a pas en soi, sur des critères strictement linguistiques, un terme qui serait bon ou juste et un autre qui serait mauvais ou erroné. Les mots se trouvent néanmoins connotés différemment en fonction des contextes socio-historiques dans lesquels ils s'énoncent. De plus, si les signifiants «feidian », «sasi » ou encore «SARS » désignent effectivement un même référent extralinguistique, et renvoient à un même signifié, leurs connotations, leurs implications idéologiques et politiques, et les traces qu'ils laissent dans une histoire culturelle varient profondément.

Les lignes suivantes se focalisent sur les enjeux politiques et idéologiques qui se cachent derrière les discours portant sur ces mots. Il s'agit de commenter et de réinscrire dans un temps historique plus long les postures idéologiques qui entourent la question du nom de ce virus. Nous nous sommes intéressés à un certain nombre d'articles développant une argumentation critique autour de l'usage de ces termes.

Depuis l'irruption de l'épidémie au printemps 2003, outre les articles dans les média traditionnels, le site internet officiel du Ministère de l'Education sur la langue et l'écriture chinoise (www.china-language.gov.cn/) propose en ligne des textes de «spécialistes» (historiens de la culture, linguistes, épidémiologiste, journalistes) soutenant de manière argumentée pour certains l'usage de «feidian », pour d'autres celui de «SARS » ou de «sasi »?.

\footnotetext{
$6 \quad$ Statistiques réalisées par l’Université des langues de Pékin, la Fédération chinoise des travailleurs des sciences de l'information et l'Institut chinois des médias en langue chinoise, tiré du Site pour la langue et l'écriture chinoise du Ministère de l'Education (RPC), (page consultée le 17/04/2004).

7 Quelques exemples de titres d'articles parus sur le Site pour la langue et l'écriture chinoise du Ministère de l'Education (RPC) entre 2003 et 2005 : Fan Jing, «Feidian' gaiming shi shibou le» (Il est temps de remplacer 'feidian') ; Zhang Jianshe, «Gei SARS ding liangge ming, rube ?» (Pourquoi ne pas donner deux noms au SARS ?) ; Zhu Jianping, Wang Yongyan, «Jianyi yong 'sasi' zuowei zhongwen yiming» (Proposition pour l'usage de 'sasi' comme traduction chinoise), Zhang Jian, «Shi 'sasi' haishi 'feidian' ?» ('sasi' ou 'feidian' ?), Ren Yujun, " Jianyi yong 'sasi’ qudai 'feidian' » (Utilisons 'sasi' plutôt que 'feidian’), Wu Jungang, "Zhongguo weihe duzhong 'feidian'? » (Pourquoi la Chine est-elle la seule nation à utiliser 'feidian'?); http:/ / www.chinalanguage.gov.cn/ (pages consultées entre 2003 et 2006). Ces articles furent, pour la plupart, aussi publiés dans le numéro spécial consacré à la terminologie du SARS de la revue Zhongguo Keji Shuyu (Chinese Science and Technology Terms Journal), Volume 2, 2003. Nous devons souligner que l'approche choisie pour cette étude
} 
TranscUlturAl, vol. 1, (4) 2011, 123-146.

http://ejournals.library.ualberta.ca/index.php/TC

Certains auteurs en appellent à la préservation de l'identité linguistique et culturelle de la Chine, alors que d'autres, à l'inverse, invoquant un souci de modernité, réclament la nécessaire adaptation de la Chine aux normes internationales et proposent un alignement sur la terminologie de l'OMS. Des commentaires se situent enfin dans un registre dont la teneur se veut plus «scientifique » en invoquant, qui les principes fondamentaux de la linguistique, qui les données épidémiologiques de la maladie pour justifier une terminologie juste.

Pour l'envoyé spécial du Quotidien du peuple à New-York, Ren Yujun, la Chine doit suivre le langage de l'OMS. Il propose une transcription phonétique de «SARS » par la construction du calque phonétique « sasi ». Selon le journaliste, les média et les autorités chinoises devraient éviter d'employer le terme « feidian» qui était pourtant l'abrégé de la terminologie adoptée par les médecins chinois qui, les premiers, ont dû faire face à cette nouvelle maladie. Ren Yujun pense que le terme « sasi» est «plus juste et plus scientifique, qu'il préserve une unité (linguistique) avec l'OMS et met la Chine en phase avec le monde ». En invoquant la « science » et « l'unité linguistique avec l'OMS », Ren loge ses propos dans une pensée qui se veut universaliste et prône le respect des normes linguistiques des instances scientifiques internationales comme étalon et comme autorité : il y a un phénomène scientifique identifiable qui, s'il s'est répandu dans différents endroits de la planète, est néanmoins partout et toujours le même et doit donc être traité comme tel. Un unique signifiant doit être la traduction dans la langue d'une méthode scientifique objective et universelle ayant identifié le virus, référent extralinguistique. La " pneumopathie atypique » s'est développée d'abord en Chine, mais, à lire Ren Yujun, la République Populaire doit faire preuve d'un « esprit d'ouverture ». Si l'appellation du virus a fait un détour par l'Occident les instances scientifiques internationales -, c'est pour revenir « plus juste » en Chine.

D'autres articles confirment que les arguments les plus récurrents pour justifier la préférence du terme «SARS » (ou de sa transcription « sasi») sur « feidian » peuvent être classés dans au moins deux discours distincts de justification qui en appellent pour l'un à la science, et pour l'autre, à la diplomatie. Puisque ce n'est qu'après avoir cerné précisément les manifestations du virus que les instances de l'OMS ont proposé le terme de « severe acute respiratory syndrome », ou «SARS », ce terme est considéré comme plus « scientifique » que celui, trop vague aux goûts des médecins, de «feidian». A la réalité scientifique s’ajoutent les exigences diplomatiques qui invitent les autorités chinoises à se mettre en phase avec le est étrangère à une méthode quantitative et ne saurait être jugée à l'aune de tels critères. 
TranscUlturAl, vol. 1, (4) 2011, 123-146.

http://ejournals.library.ualberta.ca/index.php/TC

monde. C'est dans cette perspective que le président du Comité des média de langue chinoise de Singapour pour la standardisation des termes traduits, Wu Jungang, se demande pourquoi la Chine est la seule à employer le mot «feidian »? Il commente et critique la préférence des autorités et des médias chinois pour « feidian» en écrivant que « la Chine est un pays membre de l'OMS et se doit d'avoir les mêmes pratiques que les autres, il lui faut donc se conformer à la terminologie standard de l'OMS. Si elle persiste dans sa volonté de fixer ses propres normes, elle ne fera que créer des confusions inutiles ». Cette position défend une forme d'universalisme dont les valeurs et la légitimité sont à trouver dans le discours positiviste de la science moderne et au sein des organisations internationales reconnues comme dépassant les particularismes nationaux. Ce qui gêne ici les partisans de l'usage d'une terminologie unique ne réside pas seulement dans l'universalité du phénomène du virus du SARS à proprement parler, mais plutôt dans la présence de plusieurs mots ou signifiants correspondant à plusieurs langues pour dire un même signifié.

Les scientifiques du Comité pour la standardisation des termes scientifiques pour tout le pays insistent pour changer le nom de «feidian » qui n'est pas assez scientifique à leurs yeux et pourrait porter à confusion en raison de son caractère générique : il y a en effet plusieurs types de « pneumopathie atypique ». Ils proposent l'usage temporaire de "SARS» ou du terme « chuanranxing guanz̧huang bingdu feijan ». Allant dans le même sens, Fan Jing, membre du Comité pour la standardisation des termes scientifiques pour tout le pays, estime que «le moment est venu de changer le nom de feidian $» .^{8}$ En quête d'une légitimité culturelle et scientifique, il cite à la fois les préceptes confucéens sur la juste dénomination des choses ${ }^{9}$ et les propositions du Comité faites dans un numéro spécial du Chinese Science and Technology Terms Journal. La mention de l'idée confucéenne de « juste dénomination » pour justifier son argumentation ne se limite pourtant pas ici à une simple caution culturelle, elle fait aussi figure de référence scientifique.

\section{«Feidian» garant de la transmission nationale}

Se situant dans une perspective différente, d'autres auteurs prennent le contre-pied de ces arguments et luttent pour la préservation de « feidian » selon des arguments de type

$8 \quad$ Cet article fut initialement publié dans le Keji ribao (Le Quotidien des sciences et techniques), Beijing, 14 mars 2004.

9 Zhengming, Il cite les entretiens de Confucius : «ming bu zheng ze yan bu shun» (Si les dénominations ne sont pas correctes, les paroles ne sont pas conformes). 
TranscUlturAl, vol. 1, (4) 2011, 123-146.

http://ejournals.library.ualberta.ca/index.php/TC

nationaliste visant à la défense de l'identité nationale. C'est ainsi que Zhang Jian, chercheur à l'Institut d'histoire culturelle du Sichuan, dans un article intitulé «'sasi' ou 'feidian'? », prône l'usage de ce dernier terme contre une transcription phonétique telle que « sasi ». Il évoque des arguments de bon sens : la maladie a trouvé son origine en Chine, fut découverte par des médecins chinois, ce sont donc les Chinois qui ont la meilleure connaissance du virus.

Mais sa critique se situe aussi dans une rhétorique plus nationaliste lorsqu'il dénonce ce qu'il considère comme une « pollution linguistique » et défend l'indépendance linguistique et culturelle de la Chine en faisant la remarque suivante : " ne pas entremêler la langue chinoise du vocabulaire étranger, c'est permettre la réalisation des directives politiques de l'Etat sur l'écriture, c'est protéger la pureté, la scientificité, la dignité et la beauté de la langue et de l'écriture nationale, c'est enfin poursuivre et développer notre sublime tradition culturelle. » Il est remarquable de noter que les arguments patriotiques se trouvent accompagnés d'un discours de justification scientifique.

Zhang Jian évoque des intérêts supérieurs, à savoir l'indépendance culturelle et linguistique de la Chine, pour rejeter le terme «SARS ». Il considère sa position comme étant en phase avec les directives officielles et l'attitude, à ses yeux exemplaire, des autorités chinoises : «les articles du XvI ${ }^{e}$ Congrès n'ont été mêlés d'aucun mot étranger ». Le rejet de l'hybridité supposée de la langue et de l'écriture chinoise s'accompagne ici de thèses qui appellent d'une part à la préservation des traces de l'histoire chinoise dans les mots et d'autre part l'idée, chère au nationalisme culturel, de l'antériorité d'une tradition vis à vis des influences extérieures : « le mot en chinois est antérieur à celui des occidentaux » nous dit Zhang Jian. Jun Wugang de Singapour cite dans son article les arguments d'un défenseur du terme "feidian » allant dans le sens de ce discours de l'antériorité : «Les termes chinois de maladies ne doivent pas nécessairement se conformer à ceux de l'OMS. La médecine chinoise à des origines très lointaines et nombreux sont les termes chinois antérieurs aux termes occidentaux. »

La pensée de l'antériorité est une constante d'un discours identitaire toujours en quête de traces supposées d'un passé local authentique dans le présent, gages de continuité historique d'une communauté autonome et homogène ${ }^{10}$. Invoquer l'antériorité locale d'une pratique, d'une valeur, d'un mot ou d'un discours procède d'une stratégie performative qui

10 L'anthropologue François Laplantine voit dans les invocations de l'antériorité la marque de ce qu'il appelle l'« antimétissage » (Laplantine, Nouss 83). 
TranscUlturAl, vol. 1, (4) 2011, 123-146.

http://ejournals.library.ualberta.ca/index.php/TC

tend à inventer une communauté nationale, ethnique ou culturelle en tant que «signification imaginaire sociale $»^{11}$. Cependant, dans une perspective identitaire et nationaliste, l'important ne réside pas tant dans le fait que cette antériorité soit réelle ou inventée, mais elle se doit d'être manifeste, et les traces de ce passé, garant d'authenticité culturelle, doivent être visibles dans le présent. En rejetant les termes «SARS » ou « sasi», certains auteurs critiquent l'effacement dans la langue de l'histoire de cet événement, c'est-à-dire de l'apparition en Chine du virus et de la contribution des instances chinoises au combat contre la maladie. Wu Jungang note ainsi que « c'est la contribution à la science médicale mondiale du personnel des autorités sanitaires chinoises. L'histoire ne doit pas être oubliée, la langue se doit aussi de la noter ». Les mots de la langue sont ici pris comme des éléments de preuve de la continuité historique d'une identité chinoise. Il est effectivement assuré que la langue et ses mots, n'existant pas en dehors d'un contexte social-historique donné, accompagnent, et en sont une partie intégrante, l'histoire et les traces qu'elle dépose. Nous verrons cependant que cet argument se retourne aisément contre les postures identitaires dès lors que le signifiant porte la marque d'une histoire transculturelle.

L'historien Zhang Jian ne manque pas de préciser que le terme « feidian » « contient un certain type de culture médicale et de culture nationale », c'est-à-dire que le mot se trouve investi comme représentant l'essence d'une culture nationale. L'approche de Zhang Jian, qui revendique l'authenticité d'une culture nationale en insistant sur l'identité de langue, s'inscrit dans un contexte intellectuel en Chine où s'épanouit depuis le début des années 1990 un nouveau discours de "nationalisme culturel » au sein des élites intellectuelles chinoises. Ce courant, diffus, multiple et non organisé, vise l'ensemble du champ des savoirs, allant de l'histoire à la philosophie en passant par la linguistique. Les politiques modernistes et occidentalistes de la langue et de l'écriture (simplification des caractères, projet d'alphabétisation, abandon du chinois classique, etc.) pensées, et parfois réalisées, depuis la période du 4 mai 1919 sont la cible des attaques de ce «culturalisme linguistique » ${ }^{12}$. Insistant sur une dimension « ethno-culturelle » et essentialiste de la langue et de l'écriture, et

11 «J'appelle ces significations imaginaires parce qu'elles ne correspondent pas à et ne sont pas épuisées par des références à des éléments 'rationnels' ou 'réels', et parce qu'elles sont posées par création. Et je les appelle sociales parce qu'elles n'existent qu'en étant instituées et participées par un collectif impersonnel et anonyme. » (Castoriadis 280).

12 Voir notamment le chapitre «Repossessing the mother tongue: Chinese characters, traditional forms and cultural linguistics» (Guo 91-108). 
TranscUlturAl, vol. 1, (4) 2011, 123-146.

http://ejournals.library.ualberta.ca/index.php/TC

considérant que la langue écrite traditionnelle chinoise est garante du « mode de pensée 'chinois', de la conception 'chinoise' du monde, du caractère unique de la 'Chine' », ils critiquent vigoureusement la réforme des caractères, les politiques de latinisation et la primauté de l'oral sur l'écrit de la linguistique saussurienne ${ }^{13}$. Si les idées des «culturalistes»ne sont pas encore hégémoniques aujourd'hui dans les instances officielles travaillant sur les politiques de la langue et de l'écriture, elles gagnent du terrain aujourd'hui au point que la ligne politique du Parti Communiste Chinois en matière de réformes du langage est aujourd'hui, d’après Yingjie Guo, « vague, ambiguë et contradictoire » (107).

Ces questions «identitaires » autour de la langue et des traductions de mots nouveaux ne doivent pas être regardées comme secondaires et simplement ornementales. La mention de « la pureté de la langue et de l'écriture chinoise » et l'idée que les mots seraient les garants de la transmission d'une authentique culture nationale sont autant de positionnements idéologiques qui contestent à mots couverts le nationalisme politique et modernisateur sur lequel s'est appuyée la construction de l'Etat-nation chinois depuis le début $\mathrm{du} \mathrm{xx}^{\mathrm{e}}$ siècle. Invoquer la pureté de la langue et le souhait de la préserver des « mots étrangers » implique d'accréditer le postulat d'une étanchéité et d'une homogénéité de la langue nationale dans une perspective synchronique, mais cela signifie aussi une impossibilité de regarder en face la réalité de l'histoire culturelle moderne chinoise.

\section{La traduction contre la tradition}

La mise en perspective historique de la question des mots nouveaux, de leur invention ou de leur traduction, peut éclairer le chemin parcouru par le discours identitaire chinois depuis la première révolution culturelle chinoise de 1919. La transcription et la traduction de mots ne sont pas des phénomènes nouveaux pour la Chine. Dès le $\mathrm{III}^{\mathrm{e}}$ siècle de notre ère, les lettrés chinois se sont mis à traduire les soutras du bouddhisme indien. Traduction, comme de nos jours, voulait alors aussi dire transcription d'un système de notation vers un autre (Alleton 56-59).

A l'époque moderne, c'est essentiellement à partir de la seconde moitié du $\mathrm{xx}^{\mathrm{e}}$ siècle que les mots d'origine européenne se sont répandus massivement et ont été traduits et transcrits. Ces mots correspondaient aux choses nouvelles, aux techniques modernes, et

13 Chu Xiaoquan (298) montre les évolutions du discours sur l'écriture chinoise au cours du $\mathrm{xx}^{\mathrm{e}}$ siècle en Chine, notant le retournement progressif opéré après la Révolution Culturelle. 
TranscUlturAl, vol. 1, (4) 2011, 123-146.

http://ejournals.library.ualberta.ca/index.php/TC

surtout aux concepts de la pensée philosophique, politique et scientifique de la modernité occidentale. Omniprésents aussi bien dans le langage courant que dans le langage scientifique chinois, ces mots de la modernité sont les traces de l'importance du fait transculturel, et colonial, dans l'histoire moderne chinoise. Initiée par les Jésuites qui introduisirent une terminologie notamment géographique (le globe, ou diqiu, l'équateur, ou chidao), technique (le microscope, ou xianweijing) et politique (les élections, ou xuanju), la création de néologismes par l'intermédiaire du Japon s'est intensifiée pendant la période politique transitoire entre la fin de l'Empire des Qing et la mise en place chaotique d'un régime républicain. La liste des néologismes dans le chinois standard est abondante et nullement exhaustive : de « bicyclette ", ou ziixingche, à « voiture », ou qiche, en passant par « train », ou huoche, « moteur », ou mada; ajoutons des notions fondamentales de l'économie capitaliste moderne comme " banque », ou yinhang, " consommateur », ou xiaofeiz̧he ; du politique avec « république », ou gongheguo, " communisme », ou gongchan₹̧uyi, « idéologie », ou yishixingtai; de la terminologie scientifique et médicale avec « sciences naturelles », ou ziran kexue, «tuberculose», ou jiehe; et enfin de concepts issus des sciences humaines et de la philosophie comme «subjectivité », ou z̧huguan, «abstraction », ou chouxiang, « sociologie », ou shehuixue ${ }^{14}$.

Les mots nouveaux traduits pendant la première moitié $\mathrm{du} \mathrm{xx}^{\mathrm{e}}$ siècle correspondaient à des phénomènes matériels ou conceptuels initialement apparus en Europe, qui, avec l'expansion coloniale militaire et économique des puissances européennes, se sont étendus et déplacés vers la Chine. Ils «transitaient », d'une part, directement et oralement, dans les concessions des ports ouverts de la côte où des Chinois - commerçants, compradores, traducteurs - étaient en contact avec les étrangers, mais aussi, d'autre part, indirectement, par les textes, au sein des milieux intellectuels qui lisaient et traduisaient les textes de la pensée philosophique, politique mais aussi technique et scientifique de l'« Occident ». Certains mots nouveaux se rapportaient à des réalités concrètes chinoises de l'époque alors que d'autres, signifiants flottants, renvoyaient à des concepts issus de la traduction de textes théoriques et littéraires originaires des sociétés « modernes » (espace euro-américain puis Japon) ne faisant référence à aucune réalité dans la société chinoise de l'époque.

La linguiste Viviane Alleton distingue deux types de méthodes de traductions des termes venu de l'étranger : la traduction sémantique et la traduction phonétique. Les mots

14 La liste des néologismes, et souvent des différents signifiants créés pour traduire un même concept, est loin d'être exhaustive. Lydia Liu propose une liste et un traçage de l'histoire de ces mots dans Translingual Practice (265-378). 
TranscUlturAl, vol. 1, (4) 2011, 123-146.

http://ejournals.library.ualberta.ca/index.php/TC

d'une traduction de type phonétique sont, semble-t-il, plutôt issus des échanges oraux, alors que la traduction sémantique correspond au domaine livresque. L’une des différences fondamentale entre les deux types de traductions tient à la visibilité dans le présent des origines externe d'un mot traduit phonétiquement et, au contraire, à l'absence de traces du processus de traduction pour un mot dont le sens à été privilégié lors de la traduction. Entre demokelasi et minz̧hu pour traduire "démocratie ", entre pulietaliya et wuchanjieji pour « prolétariat » ou encore lumangnide et renlei pour « humanité », se trouve impliquée la question, toujours idéologique et politique, de l'identité nationale à travers la transparence ou pas de l'histoire transculturelle des mots. Cette question de la visibilité, qui pourrait être étendue à des pratiques culturelles, des théories, des formes littéraires et artistiques, ne se limite pas à des aspects purement formels. Le choix des néologismes tend soit vers une « naturalisation » du mot et un oubli de son caractère "à l'origine non-chinois »-c'est-à-dire extérieur à l'espace socio-historique constitué par la culture des élites mandarinales, soit vers la constitution de traces, dans le langage, des interactions avec les textes et imaginaires culturels des mondes euro-américain et japonais, et donc de la visibilité d'une dimension transculturelle de l'histoire moderne chinoise. En fonction de l'esprit du temps, ces traces culturelles de métissage peuvent ne pas être considérées comme problématiques pendant une période pour se trouver ensuite effacées ou contestées dans des époques de crispation identitaire.

Si, comme le montrent les discours autour du SARS, à l'évidence, les néologismes sont un problème pour les gardiens de l'identité nationale aujourd'hui, les enjeux autour de la langue et des mots nouveaux étaient d'une tout autre nature pendant la période Républicaine. Alors que le moment contemporain en Chine est celui de la préservation et de l'affirmation de l'identité et de l'homogénéité de la « langue nationalisée chinoise », dans les années 1920, il s'agissait d'abord de l'inventer, de la populariser et de la rendre nationale. Dans la perspective d'un nationalisme politique, la dimension symbolique et culturelle de la langue est secondaire par rapport à l'idiome commun comme outil de constitution d'une communauté nationale.

\section{Le dépassement de la différence}

Dans son travail sur le cas du Japon, Naoki Sakai démontre de façon convaincante le rôle de la représentation de deux langues co-figurées en traduction dans la constitution de l'imaginaire et du concept de «langue nationale », notant ainsi l'historicité, la relativité, et 
TranscUlturAl, vol. 1, (4) 2011, 123-146.

http://ejournals.library.ualberta.ca/index.php/TC

l'hétérogénéité du contenu de cette notion. Sakai (16) relève que l'effacement des différences internes aux dites «langues nationales» est une construction historique indispensable à l'invention de ces dernières :

«Des différences conceptuelles peuvent être identifiées entre deux styles [...], entre deux dialectes régionaux, entre système idéographique et phonétique, etc. Il est possible de considérer qu'il s'agit de différences de genres, mais ce qui caractérise l'émergence de la langue nationale tient au fait que ces différences génériques, qui pourraient être représentées de façon cofigurés dans le régime de la traduction, sont toutes subsumées sous la catégorie générale de langue nationale ; ces genres [genres] doivent alors être vus comme des espèces [species] internes à la langue japonaise. »

Naoki Sakai a montré l'importance de la représentation co-figurée de deux langues traduites dans le processus historique d'invention d'objets linguistiques nationaux qui, avant la période moderne, n'étaient pas perçus comme tels. Le processus politique et linguistique de nationalisation d'une langue est récent en Chine. Il a fallu attendre les premières années du $\mathrm{xx}^{\mathrm{e}}$ siècle pour que les élites culturelles et politiques chinoises commencent à se préoccuper de l'invention d'une langue nationale à travers l'institutionnalisation et la standardisation linguistique du mandarin, ancienne langue de l'élite lettrée. Dans ses réflexions théoriques sur la traduction, le théoricien marxiste, critique culturel et traducteur prolifique Qu Qiubai (1899-1935) manifestait son désarroi en faisant le constat d'une très forte hétérogénéité linguistique du monde chinois de l'époque, cette multiplicité se traduisant non seulement par les diverses langues et dialectes locaux mais aussi par la pluralité des styles de langues écrites. Une langue commune vernaculaire en Chine, sacralisée et nationalisée aujourd'hui comme « la langue chinoise ", se trouvait seulement en situation de devenir pendant cette période républicaine.

Les intellectuels chinois, surtout ceux appartenant aux courants progressistes et occidentalistes, bien que confrontés directement aux questions concernant les mots nouveaux et les néologismes, n'envisageaient pas comme un problème la dimension étrangère d'un concept ou les traces de la traduction visible dans la forme d'un mot. A rebours d'un discours d'affirmation de la différence culturelle soutenu par la spécificité des sinogrammes chinois, tel qu'il renait aujourd'hui en Chine, les écrivains progressistes chinois, plongés dans la totalité universalisante et l'Histoire linéaire du marxisme et des pensées de l'évolution occidentale, développaient un discours s'inscrivant au contraire dans une épistémologie d'effacement de la différence entre « la Chine » et « l'Occident » (Shih 37). 
TranscUlturAl, vol. 1, (4) 2011, 123-146.

http://ejournals.library.ualberta.ca/index.php/TC

Appliqué à la langue et à la traduction, ce discours « a-culturel » tendait à faire disparaitre les différences sémantiques, morphologiques et même parfois phonétiques engendrées par le processus de traduction.

Le sort que souhaitaient réserver aux caractères des écrivains comme Lu Xun (18811936), Qian Xuantong (1887-1939) ou Qu Qiubai confirme cette logique d'effacement de la différence, largement dominante au sein de la «Culture Nouvelle» du 4 mai. Pour ces intellectuels, les caractères chinois, symboles suprême de la différence culturelle et d'une Chine ancienne rétrograde, devaient à terme disparaître. Le « problème » de la langue et de la traduction, qui toujours altère et transforme, qui toujours aussi fait ressortir la différence, devait se résoudre par la correspondance à la fois sémantique et morphologique. Pour Qu Qiubai, la latinisation de l'écriture chinoise devait être un processus naturel, une évolution nécessaire pour permettre à la Chine de s'adapter à la modernité et de recevoir le savoir scientifique de l'Occident (Villard). Les caractères étaient lus comme des signes de l'arriération et du retard temporel de la société chinoise :

«Les caractères chinois sont des momies de l'histoire du développement de la société. Bien que, fondamentalement, le développement de la langue et de l'écriture chinoise ait été limité par les conditions politiques et économiques, il est indéniable que ce développement s'est aussi trouvé contraint par les caractères chinois. » (Qu 491)

La latinisation des caractères devait permettre de « ne pas restreindre l'acquisition du vocabulaire scientifique et technique occidental et américain ».

Il est indéniable que ces conceptions critiques des intellectuels chinois vis à vis de l'écriture chinoise trouvent leurs sources théoriques dans certain a priori logocentristes et ethnocentristes de la pensée occidentale ${ }^{15}$. Mais les idées de ces intellectuels progressistes, et souvent révolutionnaires, n’étaient pas uniquement déterminées par ce que Claude LéviStrauss appelait un « faux évolutionnisme » (28). Leur objectif politique à l'époque était aussi de se sortir de la « grande tradition culturelle » dont parle Zhang Jian quand il défend l'usage

15 Tels que Jacques Derrida les a déconstruits dans son ouvrage De la grammatologie. Il démontre ainsi comment, de Rousseau à Saussure en passant par Hegel, l'écriture pictographique à été, dans un premier geste, d'abord distinguée de l'écriture dite phonétique, pour être ensuite minorée au profit de la supposée supériorité de celle-ci. On pourrait faire une histoire de ce discours et voir qu'il se loge aussi, entre autres, dans la tradition intellectuelle chinoise moderne. Derrida cite ainsi Rousseau et Hegel en exergue de son ouvrage : «Ces trois manières d'écrire répondent assez exactement aux trois divers états sous lesquels on peut considérer les hommes rassemblés en nation. La peinture des objets convient aux peuples sauvages ; les signes des mots et des propositions aux peuples barbares ; et l'alphabet aux peuples policés », "L'écriture alphabétique est en soi et pour soi la plus intelligente » (11). 
TranscUlturAl, vol. 1, (4) 2011, 123-146.

http://ejournals.library.ualberta.ca/index.php/TC

du terme «feidian », c'est à dire la culture et la langue écrite issue de classe mandarinale chinoise. L'écriture phonétique, considérée comme plus « moderne » que l'écriture chinoise, devait aussi permettre de dépasser ce médian de l'élite intellectuelle pour populariser et démocratiser les mots de la modernité dans les langues des peuples de Chine. En prônant l'écriture phonétique, ces intellectuels quittaient le référent culturel clôturé, défini et porteur de différence, des caractères pour entrer dans un espace - celui de la culture de masse ouvert, indéterminé et multiple. C'est la combinaison d'une épistémologie empruntée à la linguistique générale, d'une idéologie évolutionniste et universaliste, et d'une traduction au niveau culturel de la lutte des classes, qui poussait ces intellectuels à l'abolition des caractères chinois, symboles d'une culture honnie, et à la création d'une langue écrite chinoise au moyen du système de notation alphabétique.

A cette volonté d'effacement de la différence au niveau des écritures, s'ajoutait la nécessité de l'effacement de la différence sémantique produite par le fait de traduction. Qu Qiubai, dans ses lettres adressées à Luxun sur la question de la traduction, envisageait une équivalence absolue du sens des mots dans le processus de traduction ( $\mathrm{Qu}$ 528). Il ne reconnaît pas la non correspondance sémiologique de la traduction dont parle Walter Benjamin qui «traverse des continuums de métamorphose, non pas des zones abstraites d'équivalence et de ressemblance » (Laplantine, Nouss 563). La traduction d'un mot nouveau ne devait pas être une association de caractères préservant la tradition culturelle chinoise et faisant en sorte que les mots nouveaux soient ancrés dans le passé chinois, elle devait permettre la création d'un signifiant chinois renvoyant directement et sans ambiguïté de sens au concept auquel faisait référence le mot traduit. Qu Qiubai se loge dans l'épistémologie totalisante du signe qui "procède de la séparation du 'contenu' (ou du sens) et de la 'forme' » en considérant que l'on peut faire voyager les concepts d'une langue à l'autre, de signifiant à signifiant, dans un rapport de totale équivalence. Laplantine et Nouss, qui réfléchissent à une compréhension métisse de l'universalité, critiquent cette idéologie du signe en tant que négatrice de « la pluralité des manières de signifier » et notent que « dans la logique du sens conçu comme sens interchangeable d'une langue à une autre, on ne peut penser l'historicité du langage et du sujet, et la question de l'éthique ne se pose même pas » (575). La suppression des caractères et la quête d'une correspondance sémiotique totale entre les langues impliquait, à l'inverse du nationalisme culturel contemporain, l'effacement non pas 
TranscUlturAl, vol. 1, (4) 2011, 123-146.

http://ejournals.library.ualberta.ca/index.php/TC

des traces du fait transculturel contemporain mais de l'ancrage dans un monde socialhistorique « chinois » de la langue et de ses mots.

\section{La modernité métisse chinoise}

C'est ainsi que deux postures, l'universalisme totalisant et le nationalisme culturel, se rejoignent finalement dans une même volonté d'oubli et d'effacement de l'histoire et des traces de cette histoire dans les mots. Ce qui conteste effectivement les discours identitaires de continuité et d'homogénéité culturelle ne nous semble pas être tant l'affirmation de valeurs, de normes, scientifiques et morales, et de significations universelles qui s'élaborent toujours à partir d'une position culturelle et social-historique - parfois illégitimes d'un point de vue local - mais les traces que ne manquent pas de déposer dans les (con)textes locaux les mouvements de traduction, de réception, d'adaptation de pratiques, de mots, d'idées venus d'autres espaces linguistiques et sociaux-historiques, et qui constituent de formidables manifestations d'une réalité transculturelle déconstruisant radicalement la revendication d'authenticité du discours de l'identité ${ }^{16}$.

La Chine est tout entière parcourue par ces traces qui témoignent d'une histoire ancrée dans la modernité. Le simple fait que les élites chinoises se soient trouvées confrontées, déjà, à la question de la traduction-transcription de mots venus d'Europe pendant la première moitié $\mathrm{du} \mathrm{xx}^{\mathrm{e}}$ siècle conteste directement le discours de la continuité et de l'homogénéité culturelle et linguistique. Lorsque l'historien Zhang Jian évoque le respect de la pureté d'une "grande tradition culturelle chinoise », peut-être devrait-on lui opposer une autre tradition, « chinoise » elle aussi, celle de l'adaptation et de la réception d'éléments venus du dehors dans l'histoire moderne chinoise, une tradition de traduction et de métissage.

Le concept de «culture », parfois douteux dans son acception anthropologique, catégorie inévitable de la construction d'un discours identitaire culturaliste, se traduit par « wenhua » en chinois moderne. Les deux caractères qui le composent sont un emprunt à la langue classique des lettrés chinois, le wenyan - qui se trouvait être aussi un genre littéraire de l'élite culturelle japonaise, le kanbun, - effectué par les Japonais au cours de la période Meiji, pour traduire l'anglais « culture ». Les intellectuels réformistes chinois de la fin de l'Empire des

16 Dans «More Thoughts on Cultural Translation», Gayatri Spivak note : "What people call transculture is culture as it happens. Culture alive is its own counter-example. Transculturation is not something special and different. It is a moment in the taxinomy of the normality of what is called culture." 
TranscUlturAl, vol. 1, (4) 2011, 123-146.

http://ejournals.library.ualberta.ca/index.php/TC

Qing se sont ensuite emparés de ce néologisme sémantique du japonais moderne pour l'inscrire dans leurs textes en chinois (Liu 312). Ce mot est donc le produit d'intertextualités multiples entre des (con)textes européens, japonais et chinois. L'exemple du concept de « culture » ne saurait faire figure d'exception, il s'ajoute à celui de « civilisation », ou wenming, de « nation, race », ou minzu, de « société », ou shehui, de « monde », ou shijie, etc. La marque de la domination épistémologique d'une normativité culturelle occidentale de teneur postcoloniale se trouve ici révélée par le fait que, dans les années 1920, des mots-clés de la langue chinoise moderne tels que wenhua ou wenming étaient des signifiants pour les concepts de culture et de civilisation dans un sens normatif et universel alors qu'ils renvoyaient, en même temps, à un référent extra-linguistique qui se trouvait être la norme culturelle et le modèle de civilisation des sociétés euro-américaines. C'est ainsi qu'un dictionnaire de 1929, à l'entrée « wenhua shenghuo », ou " vie culturelle », proposait la définition suivant: "La vie culturelle correspond à la vie confortable des membres de la petite bourgeoisie. Ils habitent des maisons de type occidental, portent des soieries et des satins occidentaux et mangent des mets raffinés. »

Dans Histoire de la littérature chinoise, le sinologue Jacques Pimpaneau (18) mentionne une anecdote révélatrice qu'il situe au début du $\mathrm{xx}^{\mathrm{e}}$ siècle :

«Un lettré chinois qui avait fait un long séjour en Angleterre et collaboré à la traduction des classiques en anglais remis un jour à un général un rapport qu'il avait intitulé 'Etat de l'économie chinoise'. Le général barra le mot économie d'un coup de pinceau avec l'annotation 'nom japonais' [...] Le lettré rendit le rapport après avoir ajouté 'le mot 'nom' aussi vient du japonais'. »

La pureté linguistique et le souci d’antériorité chinoise désirés par ce général relève de l'illusion, et cette anecdote reflète l'impossibilité de renier l'histoire culturelle. En évitant l'ensemble des mots venus du dehors de la Chine, ce dernier n'aurait pas pu s'exprimer. Cet exemple est caractéristique de l'une des tensions majeures de l'histoire moderne chinoise : Comment se penser avec les mots d'une autre tradition culturelle ? Comment inventer une identité nationale - culturelle et linguistique - homogène à partir d'une histoire sociale et culturelle moderne où la Chine s'est trouvée dans une position de secondarité et d'acculturation?

De Liang Qichao, réformiste de la dernière dynastie chinoise, à Mao Zedong, la trajectoire historique chinoise au $\mathrm{xx}^{\mathrm{e}}$ siècle peut être lue comme celle de la construction politique patiente et continue de l'Etat-nation, le moment révolutionnaire et internationaliste 
TranscUlturAl, vol. 1, (4) 2011, 123-146.

http://ejournals.library.ualberta.ca/index.php/TC

ayant été une simple pause, toute relative au vu de l'ancrage idéologique nationaliste du maoïsme, dans ce mouvement de nation building ${ }^{17}$. L'identité culturelle s'inscrit dans le cadre de cette histoire en tant que problématique politique. Discours et dispositifs institutionnels ont contribué à instituer une catégorie culturelle, linguistique, ethnique et territoriale nationale chinoise. Dans ce processus, l'identité n'existe que dans sa représentation exploitée à des fins politiques, cette représentation impliquant une visibilité de la différence et de l'identité, et un marquage fort des contours de la nation. Le corollaire de la manifestation identitaire étant l'effacement des dynamiques historiques de mélanges, d'intrications et de métissages qui toujours déconstruisent l'authenticité et la pureté de l’identité.

Raconter, ou même seulement connaitre, cette histoire transculturelle des concepts et des mots de la culture de la Chine moderne rend obsolète la traditionnelle vision linéaire et étanche des histoires et des cultures nationales. Elle nous oblige à considérer une interprétation textuelle du monde en renonçant aux catégories artificielles, idéologiques et récentes des Etats-nations, des aires culturelles et des civilisations. Il est possible d'imaginer un discours sur « l'identité » de la Chine moderne qui intègre la tradition de la traduction et une certaine secondarité chinoise dans la modernité. A partir du cas chinois, peut-on penser une « universalité métisse » impliquant « non seulement l'acceptation mais la fécondation du fait que l'on n'est pas à l'origine de sa propre culture ni de sa propre langue »? (Laplantine, Nouss 574). C’est cette réalité d'une condition hybride qui fait dire à Gregory B. Lee (202) que « le spectre d'une théorie et d'une praxis non chinoises [...] hante la Chine moderne ».

La mise à jour de cette identité néologique chinoise conteste radicalement le culturalisme chinois contemporain qui tantôt néglige tantôt dénonce cet aspect de l'histoire moderne chinoise. Elle déconstruit aussi une forme dominante d'universalisme abstrait qui s'est imposé à la Chine comme au reste du monde non-occidental. Ainsi que le note Lydia Liu (26) «Quand les concepts passent de la langue d'invité à la langue d'hôte, les sens ne se trouvent pas tant 'transformés' mais plutôt inventés à l'intérieur de l'environnement local de la langue d'hôte. Dès lors, la traduction n'est plus un événement neutre laissé à l'écart des luttes idéologiques et politiques ». L'invention de néologismes par une imitation qui se trouve aussi être une métamorphose tend ainsi à déstabiliser le concept initial. Dans un contexte postcolonial, cette rencontre entre les textes du « colonisateur » et la réinvention et

$17 \quad$ Lire à ce sujet Yves Chevrier (9-45). 
TranscUlturAl, vol. 1, (4) 2011, 123-146.

http://ejournals.library.ualberta.ca/index.php/TC

réinterprétation de ces textes par le «colonisé » résultant de sa « mauvaise » lecture correspondent à ce que Homi Bhabha (179) nomme l'hybridité et l'ambivalence de la présence coloniale.

Si aujourd'hui l'Etat a fait son œuvre et construit à travers l'idéologie une conscience nationale qu'il s'applique à naturaliser par le discours, l'histoire culturelle du $\mathrm{xx}^{\mathrm{e}}$ siècle nous révèle que la nation chinoise s'est construite à partir d'une " mise en contexte mondiale » (Chevrier 375) de la Chine dans laquelle celle-ci s'est trouvée obligée de négocier une secondarité et une hybridité initiale de sa condition moderne. 
TranscUlturAl, vol. 1, (4) 2011, 123-146.

http://ejournals.library.ualberta.ca/index.php/TC

\section{BIBLIOGRAPHIE}

Alleton, Viviane. L'écriture chinoise. Paris: PUF, 2002.

Anderson, Benedict. Imagined Communities: Reflection on the Origin and Spread of Nationalism. London: Verso, 1983.

Bhabha, Homi K. Les lieux de la culture : une théorie postcoloniale. Trad. Françoise Bouillot. Paris: Payot, 2007.

Billeter, Jean-françois. Chine trois fois muette. Paris: Allia, 2000.

Billeter, Terence. L'Empereur Jaune : Une tradition politique chinoise. Paris: Les Indes Savantes, 2007.

Benkimou, Paul, Blanchard. «SARS, le roman d'un serial killer. » Le Monde 2, n²9, mai (2003).

Castoriadis Cornelius. Domaines de l'homme: Les carrefours du labyrinthe 2. Paris: Editions du Seuil, 1986.

Chakrabarty, Dipesh. Provincializing Europe: Postcolonial Thought and Historical Difference.

Princeton : Princeton University Press, 2000.

Chu, Xiaoqian. «Identité de la langue, identité de la Chine». Anne Cheng (dir.). La pensée en Chine aujourd'bui. Paris: Gallimard, 2007.

Chevrier, Yves. "Une nouvelle histoire de la Chine au xxe siècle ». Yves Michaud (dir.). La Chine aujourd'bui. Université de tous les savoirs, Odile Jacob, 2003.

Chevrier, Yves. «La culture moderne et la crise de l'Etat-nation ». Mireille Delmas-Marty, Pierre-Etienne, Will. La Chine et la démocratie. Paris: Fayard, 2007.

Derrida Jacques. De la grammatologie. Paris: Les Editions de minuit, 1967.

Guo, Yingjie. Cultural Nationalism in Contemporary China: The Search for National Identity under Reform. London: Routledge Curzon, 2004.

Lee, Gregory B. La Chine et le Spectre de l'Occident: Contestation Poétique, Modernité et Métissage. Trad. Eliane Utudjian Saint-André. Paris: Editions Syllepses, 2002.

Liu, Lydia H. Translingual Practice: Literature, National Culture, and Translated Modernity - China 1900-1937. California: Stanford University Press, 1997.

Levi-Strauss. Claude, Race et Histoire. Paris: Denoël, 1987.

Laplantine, François, Nouss, Alexis. Métissages: de Arcimboldo à Zombi. Paris: Editions Pauvert, 2001.

Pimpaneau, Jacques. Histoire de la littérature chinoise. Arles: Philippe Picquier, 1997. 
TranscUlturAl, vol. 1, (4) 2011, 123-146.

http://ejournals.library.ualberta.ca/index.php/TC

Qu, Qiubai. Qu Qiubai Wenji, tome 1. Beijing: Renmin wenxue chubanshe, 1995.

Shih, Shu-Mei. The Lure and the Modern: Writing Modernism in Semicolonial China, 1917-1937.

Berkeley: University of California Press, 2001.

Sakai, Naoki. Translation and Subjectivity: On «Japan» and Cultural Nationalism. Minneapolis: University of Minnesota Press, 1997.

Villard, Florent. Le Gramsci chinois: Penseur de la modernité culturelle. Lyon: Tigre de Papier, 2009. Zhongguo Keji Shuyu (Chinese Science and Technology Terms Journal), Volume 2, 2003, n. pag. Web, 27 Mar. 2005.

\section{SITOGRAPHIE}

Fan Jing, «Feidian' gaiming shi shihou le» (Il est temps de remplacer 'feidian'). Zhongguo Yuyan Wenzi Wang (Site internet pour la langue et l'écriture chinoise du Ministère de l'Education (RPC)), 2003, Web, 17. Mar. 2003.

Zhang Jianshe, «Gei SARS ding liangge ming, rube ?» (Pourquoi pas nommer le SARS de deux façons ?). Zhongguo Yuyan Wenz̧i Wang (Site internet pour la langue et l'écriture chinoise du Ministère de l'Education (RPC)), 2003, Web, 18. Av. 2004.

Zhu Jianping, Wang Yongyan, «Jianyi yong 'sasi' zuowei z̧hongwen yiming» (Proposition pour l'usage de 'sasi' comme traduction chinoise). Zhongguo Yuyan Wenzi Wang (Site internet pour la langue et l'écriture chinoise du Ministère de l'Education (RPC)), 2003, Web, 17. Mar. 2003.

Zhang Jian, «Shi 'sasi' haishi 'feidian' ?» ('sasi' ou 'feidian' ?). Zhongguo Yuyan Wenæi Wang (Site internet pour la langue et l'écriture chinoise du Ministère de l'Education (RPC)), 2003, Web, 17. Mar. 2003.

Ren Yujun, "Jianyi yong 'sasi' qudai 'feidian'»(Utilisons 'sasi' plutôt que 'feidian'). Zhongguo Yuyan Wenzi Wang (Site internet pour la langue et l'écriture chinoise du Ministère de l'Education (RPC)), 2003, Web, 17. Mar. 2003.

Wu Jungang, "Zhongguo weihe dushong 'feidian'? » (Pourquoi la Chine est-elle la seule nation à utiliser 'feidian'?). Zhongguo Yuyan Wenzi Wang (Site internet pour la langue et l'écriture chinoise du Ministère de l'Education (RPC)), 2003, Web, 25. Nov. 2003.

Yu Chong, "Toushi 'feidian' - SARS» (Radioscopie des mots 'feidian' et SARS). Zhongguo Yuyan Wenzi Wang (Site internet pour la langue et l'écriture chinoise du Ministère de l'Education (RPC)), 2003, Web, 30. Sep. 2003.

Shehui kexue da cidian (Grand dictionnaire des sciences sociales), Shanghai, Shijie Shuju, 1929. 
TranscUlturAl, vol. 1, (4) 2011, 123-146.

http://ejournals.library.ualberta.ca/index.php/TC

\section{Liste des caractères}

Asipiling 阿司匹林

shafa 沙發

chuanranxing feidianxing feiyan 傳染性非典型肺炎

feidian 非典

sasi 薩斯

shasi 沙斯

shashi 沙士

Guangzhou huxi jibing yanjiusuo 廣州呼吸疾病研究所

Ren Yujun 任毓駿

Wu Jungang 吳俊剛

chuanranxing guanzhuang bingdu feiyan 傳染性管狀病毒肺炎

Keji ribao 科技日報

Zhang Jian 張箭

Fan Jing 樊静

zhengming 正名

diqiu 地球

chidao 赤道

xianweijing 顯微鏡

xuanju 選舉

qiche 汽車

zixingche 自行車

huoche 火車

mada 馬達

yinhang 銀行

xiaofeizhe 消費者

gongheguo 共和國 
TranscUlturAl, vol. 1, (4) 2011, 123-146.

http://ejournals.library.ualberta.ca/index.php/TC

gongchanzhuyi 共産主義

yishixingtai 意識形態

ziran kexue 自然科學

jiehe 結核

zhuguan 主觀

chouxiang 抽象

shehuixue 社會學

demoukelasi 德谟克拉斯

minzhu 民主

pulietaliya 普列塔利亞

wuchanjieji 無産階級

lumangnide 虜芒尼德

renlei 人類

Qu Qiubai 矍秋白

Lu Xun 魯迅

Qian Xuantong 錢玄同

wenhua 文化

wenyan 文言

Kanbun 漢文 (japonais)

wenming 文明

minzu 民族

shehui 社會

shijie 世界

wenhua shenghuo 文化生活 